\title{
Maternal consumption of high-prebiotic fibre or -protein diets during pregnancy and lactation differentially influences satiety hormones and expression of genes involved in glucose and lipid metabolism in offspring in rats
}

\author{
Alannah D. Maurer ${ }^{1}$ and Raylene A. Reimer ${ }^{1,2_{*}}$ \\ ${ }^{1}$ Faculty of Kinesiology, University of Calgary, 2500 University Drive NW, Calgary, AB, Canada T2N $1 N 4$ \\ ${ }^{2}$ Department of Biochemistry and Molecular Biology, Faculty of Medicine, University of Calgary, 3330 Hospital Drive NW, \\ Calgary, AB, Canada T2N $4 N 1$
}

(Received 8 April 2010 - Revised 30 June 2010 - Accepted 8 August 2010 - First published online 6 December 2010)

\section{Abstract}

Risk of developing the metabolic syndrome may be influenced by nutritional environment early in life. We examined the effects of high-fibre (HF) and high-protein (HP) diets consumed during pregnancy and lactation on satiety hormones and expression of genes involved in glucose and lipid metabolism in offspring. Wistar dams were fed a control (C), HF or HP diets during pregnancy and lactation. At parturition, litters were culled to ten pups. At $21 \mathrm{~d}$, all pups were weaned onto C diet. At 7, 14, 21, 28 and $35 \mathrm{~d}$ after birth, blood was analysed for satiety hormones and tissues for mRNA expression in offspring. No differences were observed in litter size or birth weight. At $21 \mathrm{~d}$, offspring of HF dams had greater adjusted intestinal mass and lower liver weight than those of C but not of HP dams. Plasma glucose at $28 \mathrm{~d}$ and amylin at 7, 14 and $28 \mathrm{~d}$ were lower in HF $v$. C and HP offspring. Glucagon-like peptide- 1 was higher in HP offspring than in HF offspring at $7 \mathrm{~d}$ but was higher in HF $v$. C offspring at $21 \mathrm{~d}$. Offspring of HF dams had higher glucose transporter (GLUT2 and $\mathrm{Na}^{+}$-dependent glucose/galactose transporter) mRNA expression at $21 \mathrm{~d} v$. C and HP offspring. In brown adipose tissue, HF and HP up-regulated uncoupling protein-1 and PPAR- $\gamma$ coactivator. HP was associated with increased resistin and IL- 6 mRNA expression. The present study demonstrates that maternal diet composition differentially regulates circulating satiety hormones and genes involved in glucose transport and energy metabolism in offspring. These early changes could have long-term consequences for obesity risk.

\section{Key words: Prenatal diet: High-fibre diet: High-protein diet: Pregnancy: Development}

Prevalence of the metabolic syndrome is increasing worldwide and is characterised by hypertension, impaired glucose tolerance, dyslipidaemia and abdominal obesity ${ }^{(1)}$. The syndrome is associated with an increased risk for CVD and type 2 diabetes $^{(1)}$. The growing number of individuals considered overweight and at risk of developing the metabolic syndrome now encompasses both adults and children. It is well established that dietary modification can have a direct impact on normal physiological function, as well as on the aforementioned pathological conditions. Furthermore, there is now considerable evidence that adverse environmental influences during early development may increase disease risk in later life ${ }^{(2)}$.

The stages of development during fetal and neonatal life are critical periods when the growing organism is highly sensitive to its environment ${ }^{(3-5)}$. Developmental plasticity allows the growing fetus to respond to changes in the physiological, biochemical and nutritional environments created by the mother and placenta, and maladaptive responses to these conditions can have lasting effects ${ }^{(6)}$. There is growing evidence that a 'mismatch' between the environments encountered during development and in adulthood can increase susceptibility to disease later in life ${ }^{(2)}$. The effect of this phenomenon appears most pronounced when there is a mismatch between maternal nutritional deprivation and later nutritional affluence. Maternal overfeeding or intake of a high-fat diet during pregnancy does not appear to afford the offspring protection against obesity if they also consume a high-fat diet postnatally, and it may in fact exacerbate the negative metabolic consequences of the $\operatorname{diet}^{(7-9)}$.

Abbreviations: BAT, brown adipose tissue; C, control; $C_{\mathrm{T}}$, threshold cycle; GLP-1, glucagon-like peptide-1; HF, high fibre; HP, high protein; PGC-1 $\alpha$, PPAR- $\gamma$ coactivator; SGLT-1, $\mathrm{Na}^{+}$-dependent glucose/galactose transporter; UCP-1, uncoupling protein-1.

*Corresponding author: Dr R. A. Reimer, fax +1 403284 3553, email reimer@ucalgary.ca 
Maternal factors, including prepregnancy obesity, exert long-term influences on the health of the child ${ }^{(10)}$. Interest in understanding this interaction has grown in recent years providing the estimates that one-third of adult women in the United States are obese ${ }^{(11)}$. Excessive gestational weight gain is linked with large-for-gestational age neonates, which in turn increases the risk of developing hyperlipidaemia, insulin resistance and obesity in childhood $^{(12,13)}$. Psychological factors experienced by women, including perceived social pressure to stay thin, can influence weight gain during pregnancy ${ }^{(12)}$. Therefore, it is not unreasonable to expect that some women will continue to engage in 'fad' dieting or similar types of dietary patterns during pregnancy, including popular diets high in protein and low in carbohydrates ${ }^{(14)}$.

The consequences of poor nutrition, particularly lowprotein diets, during the prenatal period have been widely explored and shown to result in loss of pancreatic $\beta$-cells, nephrons and cardiomyocytes in offspring ${ }^{(15)}$. However, much less is known regarding overnutrition or the consumption of diets with higher levels of select nutrients. High protein (HP) intake in rats during pregnancy and lactation results in male offspring with higher blood pressure and female offspring with higher body mass and increased fat pad mass ${ }^{(16)}$. In humans, high fibre consumption during pregnancy is inversely associated with risk of pre-eclampsia ${ }^{(17)}$ and a decreased risk of gestational diabetes ${ }^{(18)}$. However, very little is known about the effects of consuming a high-fibre (HF) diet during pregnancy on the offspring. We have previously demonstrated that a HP diet introduced at weaning can increase obesity risk in adulthood whereas a high-prebiotic fibre diet in rats is protective ${ }^{(19)}$. The effects of exposure to these same HP or HF diets during prenatal growth are not known. Our objective, therefore, was to examine early (postnatal days 7-35) changes in satiety hormones and expression of genes related to glucose and lipid metabolism in the offspring of Wistar rat dams that consumed either a control (C), HF or HP diet during pregnancy and lactation. Given the critical role of the intestine in the production of satiety hormones and the pivotal roles of the liver and brown adipose tissue (BAT) in energy metabolism in young rats, these tissues were the focus of our investigations.

\section{Methods}

\section{Animals and diets}

The experimental protocol was approved by the University of Calgary Animal Care Committee and conformed to the Guide for the Care and Use of Laboratory Animals. Eighteen virgin female Wistar rats were obtained from Charles River (Montreal, QC, Canada) and housed in a temperature- and humidity-controlled room with a $12 \mathrm{~h}$ light $-12 \mathrm{~h}$ dark cycle. After acclimatisation, females were mated with Wistar males in wire-bottom cages. On the day a copulation plug was found, the females were isolated. At this time, six females were placed on each of the three experimental diets including C, HF $(21.6 \% \mathrm{w} / \mathrm{w})$ and HP $(40 \% \mathrm{w} / \mathrm{w})$ diets. Complete details of the composition of the experimental diets have been published previously ${ }^{(19)}$. The HF diet used a combination of the prebiotic fibres inulin and oligofructose $(1: 1, \mathrm{w} / \mathrm{w})$. Diets met all the nutritional requirements of pregnant, lactating and growing rats, and were formulated to be near isoenergetic by manipulating the maize starch component of the diets. The day following birth (to reduce stress in the new mothers), litters were culled to ten pups (five males and five females where possible) to minimise differences in suckling between litters. At weaning (21 d), the remaining males and females were separated and given free access to the $\mathrm{C}$ diet (AIN-93G) ${ }^{(20)}$. Food and water were provided ad libitum throughout the experiment.

On postnatal days 7, 14, 21, 28 and 35, two pups (one male and one female) from each litter were killed at approximately the same time each morning. For each diet treatment, this represents six different dams to minimise the influence of any specific dam to a diet group. Rats were anaesthetised with isoflurane, and a non-fasted blood sample was collected by cardiac puncture with the exception of 7-d-old pups where trunk blood was collected following decapitation. Due to the young age of the rats (from 7 to $35 \mathrm{~d}$ ), no overnight fast was employed, and rats were killed approximately $2 \mathrm{~h}$ before the light cycle. Blood was collected with the addition of EDTA $(1 \mathrm{mg} / \mathrm{ml})$ and aprotinin $\left(5 \times 10^{5} \mathrm{KIU} / \mathrm{l}\right)$. Diprotin A, an inhibitor of dipeptidyl peptidase IV, was added at $34 \mu \mathrm{g} / \mathrm{ml}$ (Calbiochem, La Jolla, CA, USA). Blood was centrifuged at $1600 \mathrm{~g}$ for $15 \mathrm{~min}$ at $4^{\circ} \mathrm{C}$, and plasma was stored at $-80^{\circ} \mathrm{C}$ until analysis. Following blood collection, rats were overanaesthetised, and the small intestine was excised, flushed, measured and weighed, and divided into three segments designated duodenum, jejunum and ileum. A portion of each section was snap frozen in liquid $\mathrm{N}_{2}$ and stored at $-80^{\circ} \mathrm{C}$ for later mRNA analysis. The colon, stomach, liver and BAT were also collected and stored at $-80^{\circ} \mathrm{C}$ for mRNA analysis.

\section{Plasma analysis}

A multiplex hormone assay kit and Luminex instrument were used to measure plasma hormone concentrations in the young rats according to the manufacturer's directions (Rat Endocrine LincoPlex Kit; Millipore, St Charles, MO, USA). Antibody-immobilised beads were included in the kit for analysing insulin, active glucagon-like peptide-1 (GLP-1), leptin, total amylin and glucagon concentrations. The sensitivity of the multiplex kit is $55.6 \mathrm{pm}$ for insulin and $6.2 \mathrm{pm}$ for all other analytes. Plasma glucose concentrations were measured in duplicate using a glucose trinder assay (Stanbio Laboratory, Boerne, TX, USA). 


\section{RNA extraction and real-time $P C R$}

Total RNA was extracted from the stomach, small intestine, colon, liver and BAT using Trizol reagent (Invitrogen, Carlsbad, CA, USA). Reverse transcription was performed with an input of $1 \mu \mathrm{g}$ of total RNA using the first-strand complementary DNA synthesis kit for RT-PCR (Invitrogen) with oligo $\mathrm{d}(\mathrm{T})_{15}$ as a primer. The resultant complementary DNA was amplified using primers synthesised by the University of Calgary Core DNA Services (Calgary, AB, Canada) and analysed by real-time PCR. Primer sequences have been published previously ${ }^{(19)}$. The PCR mixture was heated for $1 \mathrm{~min} 30 \mathrm{~s}$ then followed by forty cycles at $95^{\circ} \mathrm{C}$ for $30 \mathrm{~s}, 60^{\circ} \mathrm{C}$ for $30 \mathrm{~s}$ and $72^{\circ} \mathrm{C}$ for $20 \mathrm{~s}$ in a DNA iCycler apparatus (Bio-Rad, Hercules, CA, USA). A melt curve showed the melting point of the PCR product of interest. Actin was verified as a suitable housekeeping gene for the tissues of interest, and actin primers were included as an internal control in the reactions. The $2^{-\Delta C_{\mathrm{T}}}$ method $\left(\Delta C_{\mathrm{T}}=C_{\mathrm{T}}\right.$ (gene of interest) $-C_{\mathrm{T}}$ (reference gene)) was utilised for the data analysis where threshold cycle $\left(C_{\mathrm{T}}\right)$ indicates the fractional cycle number at which the amount of amplified target reaches a fixed threshold ${ }^{(21)}$. The $\Delta C_{\mathrm{T}}$ is the difference in threshold cycles between the gene of interest and actin.

\section{Statistics}

All the data are presented as means with their standard errors. A multivariate ANOVA was used to evaluate differences between diet and age groups with Tukey's post boc test. Sex effects were also analysed using multivariate analysis, and where no sex difference was found, the samples were combined for further analysis. Differences were considered significant when $P \leq 0.05$. The use of ' $n$ ' represents the number of litters examined for each parameter with one male and one female pup being selected from each litter. Statistical analyses were performed using SPSS version 16.0 software (SPSS, Inc., Chicago, IL, USA).

\section{Results}

\section{Growth parameters}

Average litter size was $15 \cdot 2$ (SEm 1.0), $15 \cdot 2$ (sem 1.0) and $13 \cdot 7$ (SEm $0 \cdot 8$ ) for $\mathrm{C}, \mathrm{HF}$ and HP offspring, respectively $(P=0 \cdot 44)$. There were an average of $7 \cdot 4$ (SEM 0.5$)$ males and $7 \cdot 4$ (SEM $0 \cdot 4)$ females per litter with no diet differences. There were no differences in birth weight between the groups $(6 \cdot 2$

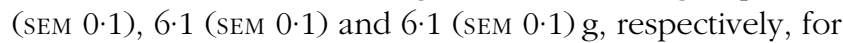
$\mathrm{C}, \mathrm{HF}$ and HP offspring). As expected with growth, body weight and the weight of the liver, stomach, small intestine and colon increased significantly with age from 7 to $35 \mathrm{~d}$ after birth $(P<0 \cdot 001)$ as did the length of the small intestine and colon $(P<0.001)$ (absolute weight data not shown). Because there was a significant sex effect for body weight from 7 to $35 \mathrm{~d}$ (i.e. males higher than females; $P<0 \cdot 05$ ), all organ weights and lengths were expressed as a proportion of individual body weight, which normalises each animal to their respective total body weight (Table 1). There were

Table 1. Organ weights of offspring adjusted for total body weight ${ }^{\star}$

(Mean values with their standard errors, $n 6$ litters)

\begin{tabular}{|c|c|c|c|c|c|c|c|c|c|c|c|}
\hline \multirow[b]{3}{*}{ Parameter } & \multirow[b]{3}{*}{ Diet } & \multicolumn{10}{|c|}{ Age (d) } \\
\hline & & \multicolumn{2}{|c|}{7} & \multicolumn{2}{|c|}{14} & \multicolumn{2}{|c|}{21} & \multicolumn{2}{|c|}{28} & \multicolumn{2}{|c|}{35} \\
\hline & & Mean & SEM & Mean & SEM & Mean & SEM & Mean & SEM & Mean & SEM \\
\hline \multirow[t]{3}{*}{ Body wt (g) } & Control & $16 \cdot 1^{a}$ & 0.9 & $37 \cdot 4^{b}$ & 1.4 & $65 \cdot 6^{c}$ & $2 \cdot 8$ & $97 \cdot 8^{d}$ & 3.5 & $150 \cdot 8^{\mathrm{e}}$ & $5 \cdot 3$ \\
\hline & Fibre & $16 \cdot 2^{\mathrm{a}}$ & 0.4 & $38 \cdot 4^{\mathrm{b}}$ & $2 \cdot 2$ & $61 \cdot 4^{c}$ & 3.2 & $99 \cdot 5^{d}$ & $5 \cdot 0$ & $144.6^{\mathrm{e}}$ & $7 \cdot 1$ \\
\hline & Protein & $16 \cdot 5^{a}$ & 1.4 & $36 \cdot 7^{b}$ & 2.4 & $60 \cdot 6^{c}$ & 4.8 & $100 \cdot 1^{d}$ & 8.0 & $146 \cdot 2^{\mathrm{e}}$ & 7.5 \\
\hline \multirow[t]{3}{*}{ Liver wt (mg/g) } & Control & $36 \cdot 8^{a, x}$ & $1 \cdot 7$ & $35 \cdot 0^{\mathrm{a}}$ & 0.4 & $39 \cdot 8^{a, b, x}$ & 0.8 & $44 \cdot 7^{\mathrm{b}, \mathrm{c}}$ & 1.0 & $44 \cdot 7^{\mathrm{b}, \mathrm{c}}$ & 0.9 \\
\hline & Fibre & $32 \cdot 8^{a, x, y}$ & 0.9 & $31 \cdot 4^{\mathrm{a}}$ & 0.6 & $36 \cdot 9^{b, y}$ & 0.7 & $43.0^{c}$ & 1.3 & $45 \cdot 0^{c}$ & 1.0 \\
\hline & Protein & $31 \cdot 3^{\mathrm{a}, \mathrm{y}}$ & 0.8 & $33 \cdot 0^{a}$ & 1.3 & $39 \cdot 1^{b, x, y}$ & 0.9 & $43 \cdot 3^{c}$ & 1.1 & $47 \cdot 6^{\mathrm{d}}$ & 1.0 \\
\hline \multirow[t]{3}{*}{ Stomach wt (mg/g) } & Control & $7 \cdot 8$ & 0.1 & 9.7 & 0.4 & $8 \cdot 0$ & 0.1 & $8 \cdot 1$ & 0.3 & $7 \cdot 2$ & 0.2 \\
\hline & Fibre & $6 \cdot 8^{\mathrm{a}}$ & 0.3 & $7.4^{\mathrm{a}}$ & 0.3 & $9.1^{\mathrm{b}}$ & 0.7 & $8 \cdot 2^{\mathrm{a}, \mathrm{b}}$ & 0.4 & $7 \cdot 4^{\mathrm{a}}$ & 0.2 \\
\hline & Protein & $7 \cdot 1^{\mathrm{a}}$ & 0.4 & $7 \cdot 3^{a}$ & 0.4 & $9.0^{\mathrm{b}}$ & 0.4 & $7 \cdot 4^{a}$ & 0.3 & $7 \cdot 4^{\mathrm{a}}$ & 0.3 \\
\hline \multirow[t]{3}{*}{ Small intestine length $(\mathrm{mm} / \mathrm{g})$} & Control & $23 \cdot 6^{\mathrm{a}}$ & 0.7 & $12 \cdot 5^{\mathrm{b}, \mathrm{x}}$ & 0.3 & $11 \cdot 2^{b, x}$ & 0.2 & $9 \cdot 2^{c}$ & 0.2 & $6 \cdot 9^{d}$ & 0.2 \\
\hline & Fibre & $23 \cdot 1^{a}$ & 0.5 & $14 \cdot 0^{\mathrm{b}, \mathrm{y}}$ & 0.4 & $12 \cdot 8^{b, y}$ & 0.4 & $9 \cdot 6^{c}$ & 0.3 & $7 \cdot 4^{\mathrm{d}}$ & 0.2 \\
\hline & Protein & $22 \cdot 1^{\mathrm{a}}$ & 0.8 & $13 \cdot 6^{b, x, y}$ & 0.3 & $12 \cdot 0^{\mathrm{b}, \mathrm{x}, \mathrm{y}}$ & 0.3 & $9 \cdot 4^{\mathrm{c}}$ & 0.4 & $7 \cdot 3^{d}$ & 0.2 \\
\hline \multirow[t]{3}{*}{ Small intestine wt $(\mathrm{mg} / \mathrm{g})$} & Control & $35 \cdot 2^{\mathrm{a}}$ & 0.4 & $27 \cdot 2^{b, x}$ & 0.8 & $28 \cdot 0^{b, x}$ & 1.0 & $29 \cdot 6^{\mathrm{b}}$ & 0.4 & $28 \cdot 1^{\mathrm{b}}$ & 0.5 \\
\hline & Fibre & $35.7^{\mathrm{a}}$ & 0.8 & $30 \cdot 6^{b, y}$ & 0.8 & $34 \cdot 2^{\mathrm{a}, \mathrm{c}, \mathrm{y}}$ & 0.7 & $31.9^{b, c}$ & 0.9 & $29 \cdot 2^{b}$ & 0.5 \\
\hline & Protein & $36 \cdot 2^{a}$ & 0.6 & $29 \cdot 3^{b, d, x, y}$ & 0.9 & $31.9^{b, y}$ & 0.7 & $30 \cdot 6^{b, c}$ & 0.6 & $29 \cdot 0^{c, d}$ & 0.5 \\
\hline \multirow[t]{3}{*}{ Colon length $(\mathrm{mm} / \mathrm{g})$} & Control & $2 \cdot 8^{\mathrm{a}}$ & 0.2 & $1.7^{\mathrm{b}}$ & 0.1 & $1 \cdot 5^{\mathrm{b}, \mathrm{c}}$ & 0.05 & $1 \cdot 2^{\mathrm{c}, \mathrm{d}}$ & 0.05 & $0.9^{d}$ & 0.03 \\
\hline & Fibre & $2 \cdot 9^{\mathrm{a}}$ & 0.2 & $1 \cdot 8^{\mathrm{b}}$ & 0.1 & $1 \cdot 6^{\mathrm{b}}$ & 0.1 & $1 \cdot 2^{\mathrm{C}}$ & 0.1 & $1.0^{\mathrm{C}}$ & 0.1 \\
\hline & Protein & $2 \cdot 9^{\mathrm{a}}$ & 0.1 & $1 \cdot 8^{\mathrm{b}}$ & 0.1 & $1.5^{\mathrm{c}}$ & 0.1 & $1 \cdot 2^{d}$ & 0.1 & $0.9^{e}$ & 0.1 \\
\hline \multirow{3}{*}{ Colon wt (mg/g) } & Control & $2 \cdot 8^{\mathrm{a}, \mathrm{x}}$ & 0.3 & $2 \cdot 6^{\mathrm{a}}$ & 0.3 & $4 \cdot 4^{\mathrm{b}, \mathrm{x}}$ & 0.2 & $5 \cdot 6^{c}$ & 0.3 & $5 \cdot 2^{\mathrm{b}, \mathrm{c}}$ & 0.2 \\
\hline & Fibre & $2 \cdot 1^{a, y}$ & 0.1 & $4 \cdot 5^{\mathrm{a}, \mathrm{b}}$ & 1.6 & $5 \cdot 9^{\mathrm{b}, \mathrm{y}}$ & 0.4 & $5 \cdot 8^{\mathrm{b}}$ & 0.4 & $5 \cdot 5^{\mathrm{b}}$ & 0.3 \\
\hline & Protein & $2 \cdot 9^{\mathrm{a}, \mathrm{x}}$ & 0.1 & $3.2^{\mathrm{a}}$ & 0.3 & $4 \cdot 4^{\mathrm{b}, \mathrm{x}}$ & 0.2 & $5 \cdot 3^{b}$ & 0.2 & $4.9^{b}$ & 0.2 \\
\hline
\end{tabular}

a,b,c,d,e Mean age difference values with unlike superscript letters within a row were significantly different $(P<0.05)$.

${ }^{x, y}$ Mean diet difference values with unlike superscript letters within an age group were significantly different $(P<0.05)$.

* One male and one female pup from each litter. 

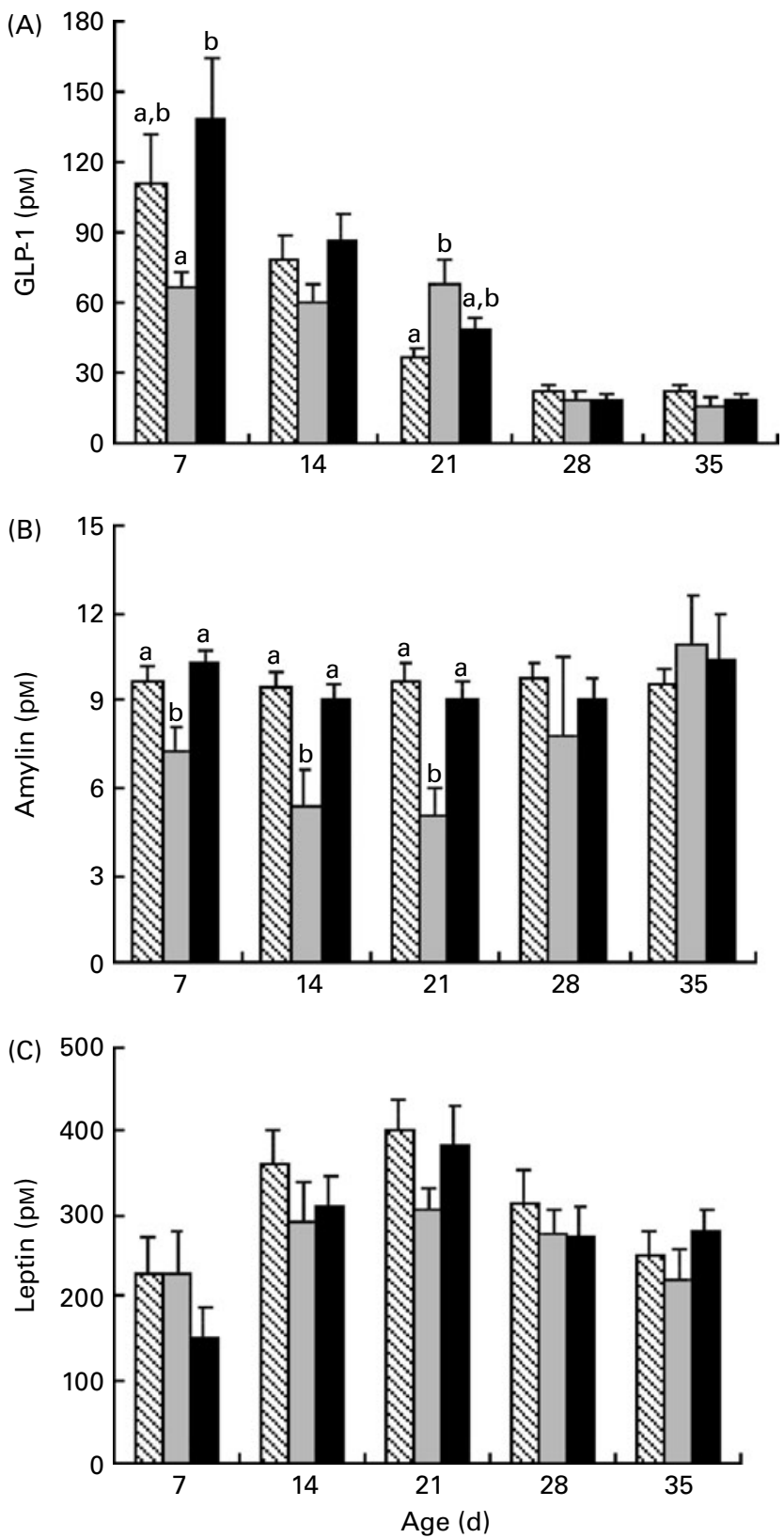

Fig. 1. Plasma concentrations of (A) glucagon-like peptide-1 (GLP-1), (B) amylin and (C) leptin in offspring of dams consuming control, high-fibre or high-protein diets during pregnancy and lactation. Values are means with their standard errors, $n 6$ litters with one male and one female pup from each litter. There was no significant sex effect for the hormones; therefore data of male and female pups were combined for analysis. ${ }^{a, b}$ Mean values within an age group with unlike letters were significantly different among the diets $(P<0.05)$. There were significant age effects, independent of diet, for GLP-1 wherein each day was different from every other day $(P<0.001)$ except 28 and $35 \mathrm{~d}$ which were not different. For leptin, age effects were found wherein the concentration at $7 \mathrm{~d}$ was different from 14,21 and $28 \mathrm{~d}(P<0.05)$ and the concentration at $21 \mathrm{~d}$ was different from $35 \mathrm{~d}(P=0.003)$. $\mathbb{\mathbb { N }}$, Control; $\square$, fibre; $\mathbf{\square}$, protein.

no sex effects for any of the physical characteristics when expressed as a proportion of total body weight; therefore males and females were combined. There was a significant effect of diet, where adjusted liver weight was greater in $\mathrm{C} v$. HP offspring at $7 \mathrm{~d}(P=0.01)$ and greater in $\mathrm{C} v$. HF offspring
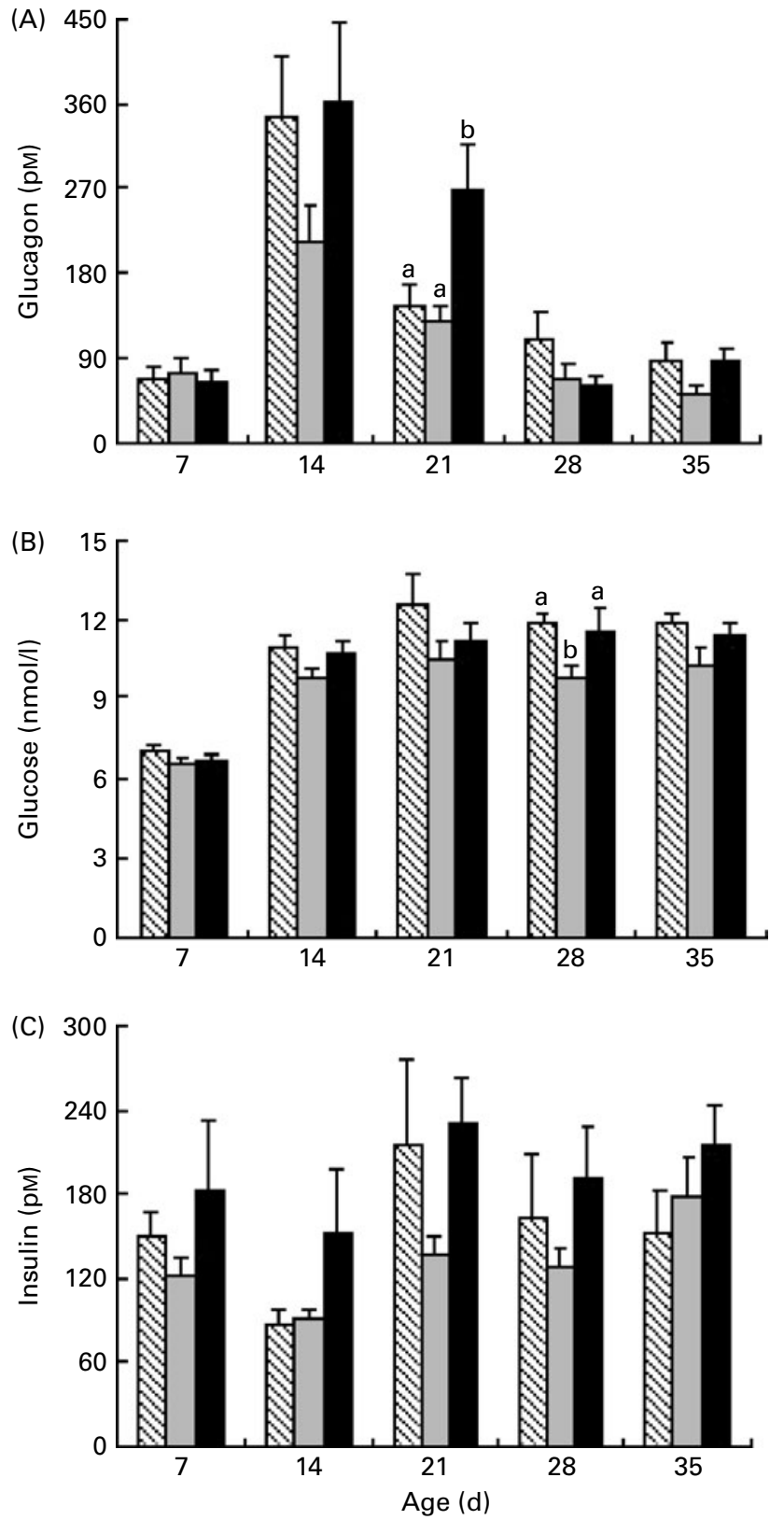

Fig. 2. Plasma concentrations of $(A)$ glucagon, $(B)$ glucose and $(C)$ insulin in offspring of dams consuming control, high-fibre or high-protein diets during pregnancy and lactation. Values are means with their standard errors, $n 6$ litters with one male and one female pup from each litter. There was no significant sex effect for the hormones, therefore data of male and female pups were combined for analysis. ${ }^{\mathrm{a}, \mathrm{b}}$ Mean values within an age group with unlike letters represent significant difference among the diets $(P<0.05)$. There were significant age effects, independent of diet, for insulin wherein the concentration at $7 \mathrm{~d}$ was different from 14 and $21 \mathrm{~d}(P<0.001)$, the concentration at $14 \mathrm{~d}$ was different from all other days $(P<0.001)$ and the concentration at $21 \mathrm{~d}$ was different from all other days $(P<0.001)$. For glucose, an age effect was found wherein the concentration at $7 \mathrm{~d}$ was different from all other days $(P<0.001)$.

at $21 \mathrm{~d}(P=0 \cdot 04)$. Adjusted small intestine length was greater in HF $v$. C offspring at $14 \mathrm{~d}(P=0.02)$ and $21 \mathrm{~d}(P=0.002)$. Adjusted small intestine weight was greater in HF $v$. C offspring at $14 \mathrm{~d}(P=0.03)$ and greater in HF and HP $v$. C offspring at $21 \mathrm{~d}(P=0.001$ and 0.004 , respectively). Adjusted 
colon weight was lower in HF $v$. C and HP offspring at $7 \mathrm{~d}$ $(P=0.01$ and 0.02 , respectively) and higher in HF $v$. C and HP offspring at $21 \mathrm{~d}(P=0.005$ and 0.004 , respectively). There were significant age effects for all physical characteristics examined $(P<0.05)$.

\section{Plasma hormones and glucose}

Concentrations of plasma GLP-1, amylin, leptin, insulin, glucagon and glucose are presented in Figs. 1 and 2. On postnatal day 7 , offspring of $\mathrm{HF}$ dams had significantly lower active GLP-1 than that of HP dams $(P=0.03)$, whereas by $21 \mathrm{~d}$, HF offspring had higher GLP-1 levels than $\mathrm{C}$ offspring $(P=0.01)$ (Fig. 1(A)). Amylin was lower in $\mathrm{HF}$ offspring than in $\mathrm{C}$ and $\mathrm{HP}$ offspring at $7 \mathrm{~d}$ $(P<0.05), 14 \mathrm{~d}(P<0.01)$ and $21 \mathrm{~d}(P<0.001)$ (Fig. 1(B)). Glucagon was higher in HP offspring than in $\mathrm{C}(P=0.03)$ and $\mathrm{HF}$ offspring $(P=0.01)$ at $21 \mathrm{~d}$ (Fig. 2(A)). Glucose was lower in HF offspring at $28 \mathrm{~d}$ than in $\mathrm{C}$ and $\mathrm{HP}$ offspring $(P<0.05)$ (Fig. 2(B)).

Independent of diet, there was a significant effect of age for GLP-1 wherein plasma concentrations decreased from $7 \mathrm{~d}$ towards $35 \mathrm{~d}$ with each day being different from the others $(P<0.001)$ except where concentrations at 28 and $35 \mathrm{~d}$ were not different (Fig. 1(A)). There was a significant effect of age for leptin wherein concentrations at $7 \mathrm{~d}$ were lower than at 14, 21 and $28 \mathrm{~d}(P<0.05)$, and were higher at $21 \mathrm{~d}$ than at $35 \mathrm{~d}(P=0.003)$ (Fig. 1(C)). Insulin was lower at $14 \mathrm{~d}$ than at $21 \mathrm{~d}(P=0.03)$ (Fig. 2(C)). Glucagon was lower at $7 \mathrm{~d}$ than at 14 and $21 \mathrm{~d}(P<0.001)$, higher at $14 \mathrm{~d}$ than all other days $(P<0.001)$ and different at $21 \mathrm{~d}$ from all other days $(P<0.001)$ (Fig. 2(A)). For glucose, an age effect was observed wherein values were lower at $7 \mathrm{~d}$ than all other days $(P<0.001)$ (Fig. 2(B)).

\section{Intestinal gene expression}

In the jejunum, GLUT5 mRNA levels were higher in HF offspring at $28 \mathrm{~d}$ than those in $\mathrm{C}(P=0.043)$ offspring (Fig. 3). At $21 \mathrm{~d}, \mathrm{Na}^{+}$-dependent glucose/galactose transporter (SGLT-1) mRNA levels were significantly higher in $\mathrm{HF}$ rats than those in both $\mathrm{C}(P<0.001)$ and HP offspring $(P=0.01)$ (Fig. 3). At $28 \mathrm{~d}$, SGLT-1 mRNA in HF rats was higher than in HP rats $(P=0 \cdot 012)$, and at $35 \mathrm{~d}$, SGLT-1 mRNA was higher in both HF and HP offspring than in $\mathrm{C}$ offspring ( $P=0.025)$. There were no significant diet differences for GLUT2, GLUT5 or SGLT-1 in the duodenum of HF or HP offspring compared with $\mathrm{C}$ offspring, but GLUT5 mRNA levels were higher in HF $v$. C and HP offspring in the ileum at $28 \mathrm{~d}(P<0.05)$ (Fig. 3). There was no difference in proglucagon expression in the intestine and no diet effect for stomach ghrelin or colon peptide
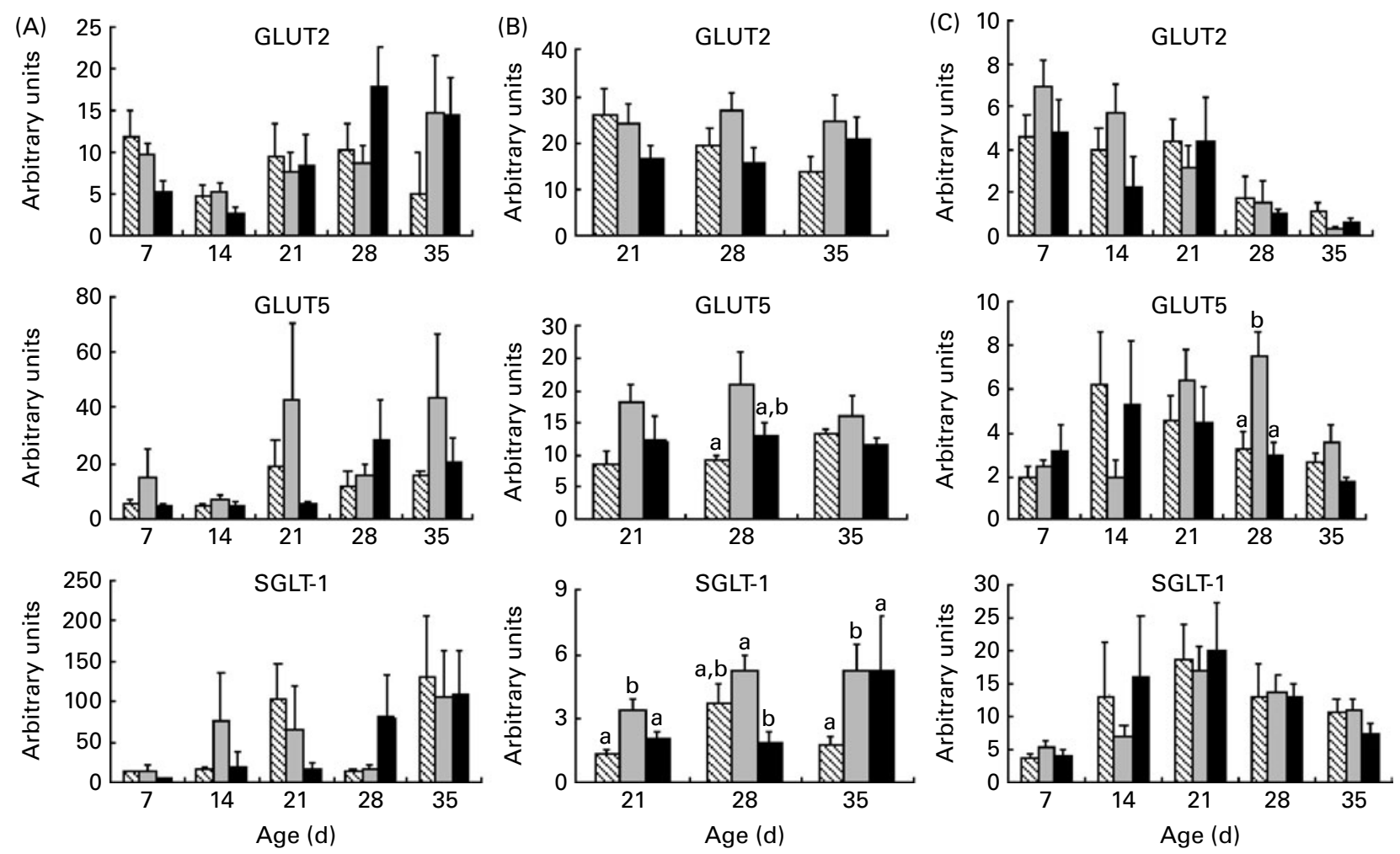

Fig. 3. GLUT2, GLUT5 and $\mathrm{Na}^{+}$-dependent glucose/galactose transporter (SGLT-1) mRNA expression in the duodenum (A), jejunum (B) and ileum (C) in offspring from $7 \mathrm{~d}$ through $35 \mathrm{~d}$. Due to the very limited intestinal tissue in pups at 7 and $14 \mathrm{~d}$, the small intestine was divided into equal segments and designated as the upper and lower halves of the small intestine. The upper half is represented in the duodenum graphs, and the lower half is represented in the ileum graph. Values are means with their standard errors $(n 6) .{ }^{a, b}$ Mean values within an age group, with unlike letters represent significant differences among the diets $(P<0.05)$. $\mathbb{Q}$, Control; $\square$, high fibre; $\mathbf{\square}$, high protein. 

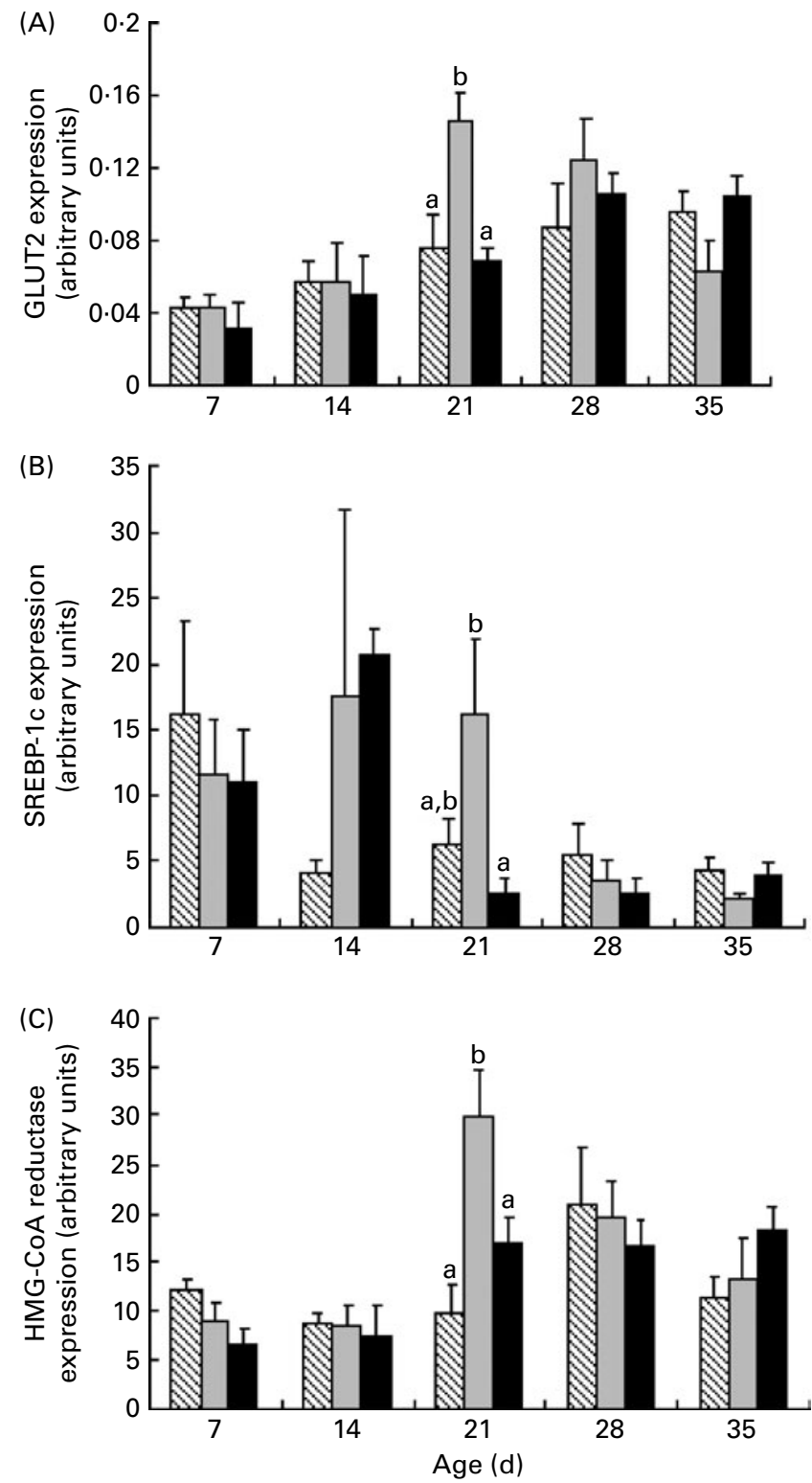

Fig. 4. Hepatic (A) GLUT2, (B) sterol regulatory element binding protein-1c (SREBP-1C) and (C) 3-hydroxy-3-methylglutaryl-CoA reductase (HMG-CoA reductase) expression in offspring. Values are means with their standard errors $(n 6)$. ${ }^{a, b}$ Mean values within an age group with unlike letters represent significant differences among the diets $(P<0.05)$. $\mathbb{\mathbb { N }}$, Control; $\square$, high fibre; ם, high protein.

YY expression. Independent of diet, there were significant age effects for SGLT-1 mRNA in the jejunum, wherein SGLT-1 mRNA was greater at $28 \mathrm{~d}$ (3.7 (SEM 0.9) arbitrary units) than at $21 \mathrm{~d}(1.3$ (SEM $0 \cdot 3)$ arbitrary units). In the ileum, SGLT-1 mRNA was greater at 21d (18.6 (sEm $5 \cdot 2)$ arbitrary units) than at $7 \mathrm{~d}(3.5$ (SEM 1.0$)$ arbitrary units).

\section{Hepatic gene expression}

The HF diet was associated with higher hepatic GLUT2 mRNA at $21 \mathrm{~d}$ than the $\mathrm{C}(P=0.021)$ and HP diets $(P=0.003)$ (Fig. 4(A)). At $21 \mathrm{~d}$, the $\mathrm{HF}$ diet resulted in higher sterol regulatory element binding protein-1c

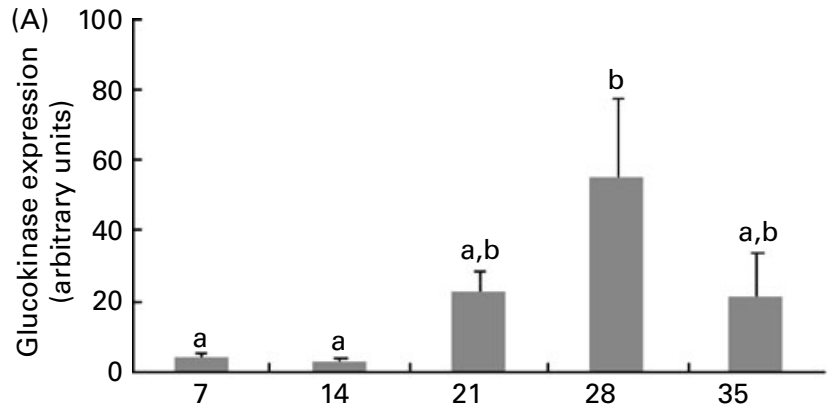

(B)

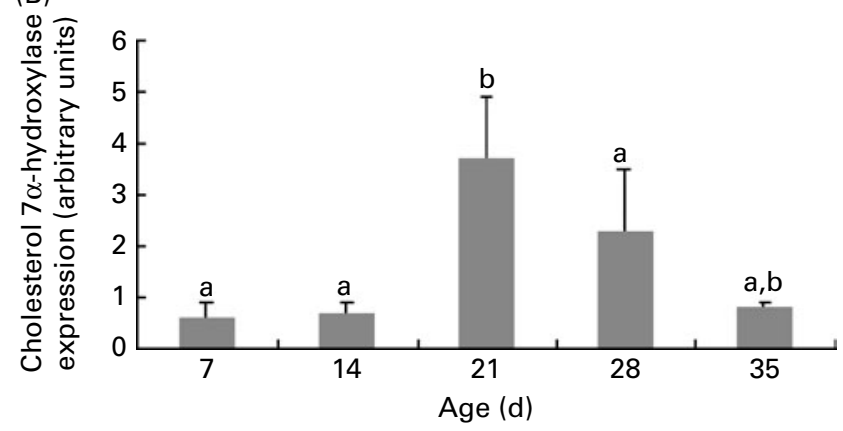

Fig. 5. Age effects on hepatic gene expression in control rats. Values are means with their standard errors $(n 6)$. ${ }^{a, b}$ Mean values with unlike letters were significantly different $(P<0.05)$. Glucokinase mRNA $(A)$ expression at $28 \mathrm{~d}$ was higher than at both $7 \mathrm{~d}(P=0.04)$ and $14 \mathrm{~d}(P=0.03)$. Cholesterol $7 \alpha$-hydroxylase mRNA (B) expression was higher at $21 \mathrm{~d}$ than at $7 \mathrm{~d}$ $(P=0.02), 14 \mathrm{~d}(P=0.02)$ and $35 \mathrm{~d}(P=0.03)$.

mRNA than the HP diet $(P=0 \cdot 048)$ (Fig. 4(B)). At $21 \mathrm{~d}$, the offspring of HF dams had higher 3-hydroxy-3-methylglutaryl-CoA reductase mRNA than that of $\mathrm{C}(P=0.007)$ and HP dams $(P=0.045)$ (Fig. $4(\mathrm{C}))$. There was a significant age effect for hepatic glucokinase and cholesterol $7 \alpha$-hydroxylase $(P<0.05)$ wherein $28 \mathrm{~d}$ was greatest for glucokinase mRNA and $21 \mathrm{~d}$ was greatest for cholesterol 7 $\alpha$-hydroxylase mRNA (Fig. 5).

\section{Brown adipose tissue gene expression}

Uncoupling protein-1 (UCP-1) mRNA levels were higher in $\mathrm{HP}$ and $\mathrm{HF}$ offspring than in $\mathrm{C}$ offspring at 7, 21 and $35 \mathrm{~d}$; higher UCP-1 at $28 \mathrm{~d}$ was solely in HF offspring than in C offspring (Fig. 6). At 14 and 35 d, PPAR- $\gamma$ coactivator (PGC-1 $\alpha$ ) mRNA levels were higher in HF and HP offspring than in $\mathrm{C}$ offspring, while fatty acid synthase mRNA was lower at $7 \mathrm{~d}$ in $\mathrm{HP}$ and $\mathrm{HF}$ offspring than in $\mathrm{C}$ offspring and lower in HP offspring than in $\mathrm{C}$ offspring at $21 \mathrm{~d}$ (Fig. 6). Resistin mRNA was significantly higher in HP offspring than in HF offspring at $7 \mathrm{~d}$ and higher than in $\mathrm{C}$ offspring at 21 and $28 \mathrm{~d}$. IL-6 mRNA at $35 \mathrm{~d}$ was significantly higher in $\mathrm{HP}$ (1.75 (sem 0.5)) than in C offspring (0.21 (sem 0.04); $P=0 \cdot 01)$ but not in HF offspring (0.87 (sem 0.15); $P=0 \cdot 48)$.

\section{Discussion}

The present study demonstrates that manipulation of fibre and protein contents in maternal diet during pregnancy 

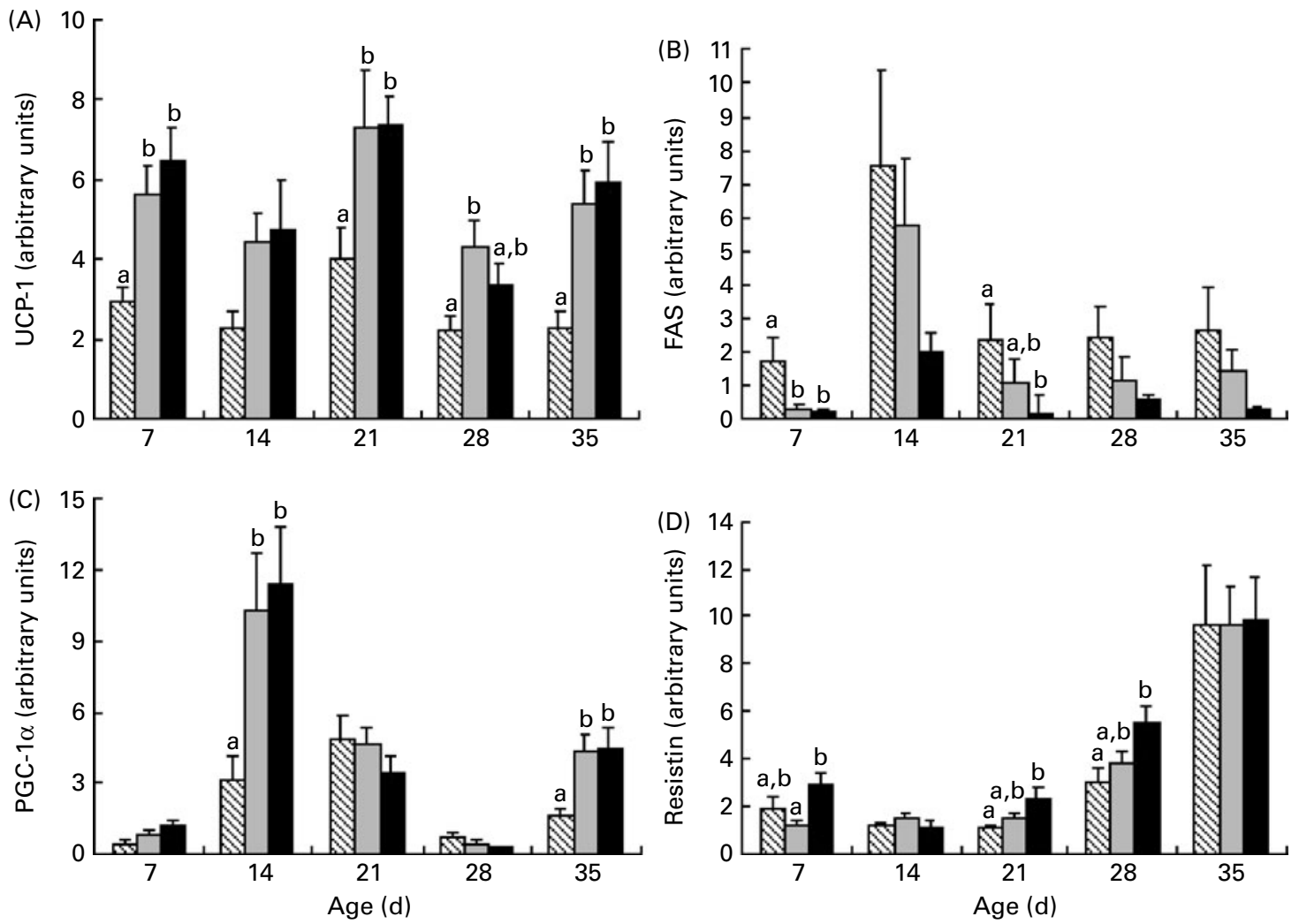

Fig. 6. Uncoupling protein-1 (UCP-1) (A), fatty acid synthase (FAS) (B), PPAR- $\gamma$ coactivator (PGC-1 $\alpha$ ) (C) and resistin (D) mRNA levels in brown adipose tissue in offspring of dams fed high-fibre or high-protein diets during pregnancy and lactation. Individual graphs represent UCP-1, FAS, PGC-1 $\alpha$ and resistin mRNA levels from $7 \mathrm{~d}$ to $35 \mathrm{~d}$. Results are presented as means with their standard errors $(n 6) .{ }^{a, b}$ Mean values within an age group with unlike letters represent significant differences among the diets $(P<0.05)$. $\mathbb{Q}$, Control; $\square$, fibre; $\mathbf{\square}$, protein.

and lactation is associated with early changes in the secretion of select satiety hormones and the expression of genes involved in glucose and lipid metabolism in offspring. Our major findings include (1) an increase in small intestine and colon weight in offspring of dams fed the HF diet at 14 and $21 \mathrm{~d}$; (2) lower plasma amylin in offspring of HF dams at 7, 14 and $21 \mathrm{~d}$; (3) increased expression of the intestinal sugar transporters GLUT5 and SGLT-1 and hepatic cholesterol regulatory genes with the $\mathrm{HF}$ diet and (4) finally, while both the HP and HF diets increased UCP-1 and PGC- $1 \alpha$ mRNA in BAT, only the HP diet increased resistin and IL-6 mRNA levels. These findings highlight the potential for indirect exposure to nutrients via maternal diet to influence the physical and functional characteristics of the gastrointestinal tract and the expression of genes in two organs that are intimately linked to energy homeostasis in the young rat, the liver and the BAT.

\section{Hormone profiles and glycaemia}

Several outcomes suggest that the HF offspring exhibit favourable metabolism. For example, the greater GLP-1 and lower glucagon levels observed at $21 \mathrm{~d}$ and the lower glucose observed at $28 \mathrm{~d}$ in the $\mathrm{HF}$ offspring are reflective of better glycaemic control than those observed in the $\mathrm{C}$ and HP offspring. In the BAT, HF offspring exhibit higher UCP-1 and PGC- $1 \alpha$ and lower fatty acid synthase and resistin mRNA, which reflects a pattern previously shown to enhance insulin sensitivity ${ }^{(22,23)}$. On the contrary, amylin, which decreases food intake ${ }^{(24)}$ was lower in HF offspring before weaning at 7, 14 and $21 \mathrm{~d}$. The implication of this reduction before $21 \mathrm{~d}$ is not clear given that levels rebounded to control values post-weaning.

\section{Physical characteristics of the gut}

Our data showing an increase in the relative mass of the small intestine and colon are consistent with previous studies in adult rats with fibre-enriched diets ${ }^{(25-27)}$. While addition of fermentable fibres to a diet is known to cause a significant proliferative effect in the gut ${ }^{(28)}$, it is interesting that this trophic effect occurred via indirect exposure to the maternal HF diet. To what degree a fibre-rich diet alters the composition of maternal milk is not known, but maternal lipid intake has been shown to alter daily milk volume and lipid production, milk lipid concentration and daily output of protein and lactose ${ }^{(29)}$. Oligosaccharides, which are carbohydrate polymers that increase the numbers of health-promoting bacteria in the 
gut and thereby fuel colonocytes, are the fourth largest contributor to the composition of breast milk by weight ${ }^{(30)}$. Determining the levels of oligosaccharides in milk from dams consuming HF or HP diets could identify differences in milk composition that explain in part the differential growth of the gut. It is also plausible that limited direct exposure to the diets may have occurred when pups begin to 'sample' the diet of the dams as they approached weaning ${ }^{(31)}$.

\section{Intestinal gene expression}

Sugar transport in the intestine is mediated by various transporters, including GLUT2, GLUT5 and SGLT-1 ${ }^{(32)}$. GLUT2 and SGLT-1 are present well before birth, whereas GLUT5 expression remains low until weaning is complete ${ }^{(33)}$, but can be precociously enhanced during weaning with fructose intake ${ }^{(34)}$. Massimino et al. ${ }^{(35)}$ demonstrated that fermentable fibres increase GLP-1 secretion and improve glucose homeostasis in dogs, despite increasing intestinal uptake of glucose and up-regulation of GLUT2 and SGLT-1 mRNA levels in the jejunum and ileum. The higher GLUT5 and SGLT-1 mRNA that we observed fits with that data, however, occurred after the offspring had been weaned onto the $\mathrm{C}$ diet.

\section{Hepatic gene expression}

Contrary to what might be expected, expression of sterol regulatory element binding protein-1c and 3-hydroxy-3methylglutaryl-CoA reductase was higher in the $\mathrm{HF}$ offspring at $21 \mathrm{~d}$ than that in the $\mathrm{C}$ and $\mathrm{HP}$ offspring. We have shown similar up-regulation of these genes with 10 and $20 \%$ oligofructose/inulin diets in a genetically obese rat model ${ }^{(36)}$. Prebiotic fibres have the potential to bind bile in the gut and in turn reduce hepatic exposure to bile salts. Feedback to the liver triggers endogenous cholesterol production which would be reflected in the up-regulation of genes controlling synthesis ${ }^{(36)}$. It is difficult, however, to reconcile the effects of direct exposure to these fibres and binding of bile salts with the indirect exposure that the HF offspring experienced in the present study.

\section{Brown adipose tissue gene expression}

While the primary role of white adipose tissue is to store excess energy, BAT is primarily responsible for burning fat to generate heat through non-shivering thermogenesis ${ }^{(37)}$. HP diets have been shown to increase UCP-1 mRNA in BAT $^{(38)}$ and to increase PGC- $1 \alpha$ protein expression in muscle ${ }^{(39)}$. Conversely, very little work has examined the effects of a HF diet on UCP-1 and PGC- $1 \alpha$. In voles, a HF diet did not alter UCP-1 content in $\mathrm{BAT}^{(40)}$, and in rats, a $5 \%$ inulin diet did not alter hepatic PGC-1 $\alpha \mathrm{mRNA}^{(41)}$. An explanation for the differences between these studies and our work in which the HF diet did increase UCP-1 mRNA at four time points and PGC- $1 \alpha$ mRNA at two time points than the $\mathrm{C}$ diet could relate not only to the different tissues examined (hepatic $v$. BAT), but also to the higher dose of fibre that we utilised $^{(41)}$. We also observed higher resistin and IL-6 mRNA in HP offspring. Increased resistin and IL-6 are associated with reduced insulin sensitivity. While Stroubini et al. ${ }^{(42)}$ showed that a HP diet increases serum resistin in Wistar rats more so than a high-carbohydrate diet, the contribution of BAT to overall circulating resistin may be limited given its chief production in white adipose tissue in rodents and macrophages in humans ${ }^{(23)}$. Both clinical ${ }^{(43,44)}$ and experimental ${ }^{(45,46)}$ studies demonstrate that increased fibre intake is associated with reduced plasma IL-6 but not IL-6 mRNA in white adipose tissue ${ }^{(47)}$. In the present study, the HP diet increased IL- 6 mRNA in BAT over C diet levels but not over HF levels, suggesting that measurement of circulating adipokine levels is probably needed to assess the true effects of the HF diet on systemic inflammation and metabolic syndrome risk.

In conclusion, it is clear that altering the fibre and protein contents of maternal diet during pregnancy and lactation has the potential to alter metabolism in offspring. At present, it is not possible to state whether differences in maternal diet composition alone contributed to the differences observed in the offspring given that the HF dams also had lower food intake during pregnancy (MC Hallam and RA Reimer, unpublished results). Whether or not the profile of satiety hormones and the expression of numerous genes involved in glucose and lipid metabolism observed in rats in the present study during early postnatal life have persistent effects on metabolism and alter susceptibility to obesity and type 2 diabetes warrants further investigation.

\section{Acknowledgements}

We thank Kristine Lee for her extensive technical help in the present study. The present work was supported by the Natural Sciences and Engineering Research Council of Canada. A. D. M. was supported by a training grant from the Julia MacFarlane Diabetes Research Centre. A. D. M. participated in the design and execution of the study, carried out the plasma analysis, performed statistical analysis and drafted the manuscript. R. A. R. conceived of the study, participated in its design and coordination and edited the manuscript. The authors declare no conflict of interest.

\section{References}

1. Joy T, Lahiry P, Pollex RL, et al. (2008) Genetics of metabolic syndrome. Curr Diab Rep 8, 141-148.

2. Godfrey KM, Lillycrop KA, Burdge GC, et al. (2007) Epigenetic mechanisms and the mismatch concept of the 
developmental origins of health and disease. Pediatr Res $\mathbf{6 1}$, 5R-10R.

3. Barker DJ (2004) The developmental origins of adult disease. J Am Coll Nutr 23, 588S-595S.

4. Angelbeck JH \& DuBrul EF (1983) The effect of neonatal testosterone on specific male and female patterns of phosphorylated cytosolic proteins in the rat preoptichypothalamus, cortex and amygdala. Brain Res 264, 277-283.

5. Maloney CA \& Rees WD (2005) Gene-nutrient interactions during fetal development. Reproduction 130, 401-410.

6. Lucas A (1998) Programming by early nutrition: an experimental approach. J Nutr 128, 401S-406S.

7. Bruce KD, Cagampang FR, Argenton M, et al. (2009) Maternal high-fat feeding primes steatohepatitis in adult mice offspring, involving mitochondrial dysfunction and altered lipogenesis gene expression. Hepatology $\mathbf{5 0}$, 1796-1808.

8. Bayol SA, Farrington SJ \& Stickland NC (2007) A maternal 'junk food' diet in pregnancy and lactation promotes an exacerbated taste for 'junk food' and a greater propensity for obesity in rat offspring. BrJ Nutr 98, 843-851.

9. Bayol SA, Simbi BH, Bertrand JA, et al. (2008) Offspring from mothers fed a 'junk food' diet in pregnancy and lactation exhibit exacerbated adiposity that is more pronounced in females. J Physiol 586, 3219-3230.

10. Salsberry PJ \& Reagan PB (2005) Dynamics of early childhood overweight. Pediatrics 116, 1329-1338.

11. ACOG Committee Opinion Number 315 (2005) Obesity in pregnancy. Obstet Gynecol 106, 671-675.

12. Smith SA, Hulsey $\mathrm{T} \&$ Goodnight W (2008) Effects of obesity on pregnancy. J Obstet Gynecol Neonatal Nurs 37, 176-184.

13. Stotland NE, Cheng YW, Hopkins LM, et al. (2006) Gestational weight gain and adverse neonatal outcome among term infants. Obstet Gynecol 108, 3 Pt 1, 635-643.

14. Atkins RC (1992) Dr. Atkins' New Diet Revolution. New York: Avon Books.

15. McMillen IC, MacLaughlin SM, Muhlhausler BS, et al. (2008) Developmental origins of adult health and disease: the role of perconceptional and foetal nutrition. Basic Clin Pharmacol Toxicol 102, 82-89.

16. Thone-Reineke C, Kalk P, Dorn M, et al. (2006) High-protein nutrition during pregnancy and lactation programs blood pressure, food efficiency, and body weight of the offspring in a sex-dependent manner. Am J Physiol Regul Integr Comp Physiol 291, R1025-R1030.

17. Qui C, Coughlin KB, Frederick IO, et al. (2008) Dietary fiber intake in early pregnancy and risk of subsequent preeclampsia. Am J Hypertens 21, 903-909.

18. Zhang C, Liu S, Solomon CG, et al. (2006) Dietary fiber intake, dietary glycemic load, and the risk for gestational diabetes mellitus. Diabetes Care 29, 2223-2230.

19. Maurer AD, Chen Q, McPherson C, et al. (2009) Changes in satiety hormones and expression of genes involved in glucose and lipid metabolism in rats weaned onto diets high in fiber or protein reflect susceptibility to increased fat mass in adulthood. J Physiol Lond 587, 679-691.

20. Reeves PG, Nielsen FH \& Fahey GC Jr (1993) AIN-93 purified diets for laboratory rodents: final report of the American Institute of Nutrition ad boc writing committee on the reformulation of the AIN-76A rodent diet. J Nutr 123, $1939-1951$.

21. Livak KJ \& Schmittgen TD (2001) Analysis of relative gene expression data using real-time quantitative PCR and the $2^{-\Delta \Delta C_{\mathrm{T}}}$ method. Methods 25, 402-408.

22. Liang H \& Ward WF (2006) PGC-1á: a key regulator of energy metabolism. Adv Physiol Educ 30, 145-151.
23. Barnes KM \& Miner JL (2009) Role of resistin in insulin sensitivity in rodents and humans. Curr Protein Pept Sci 10, 96-107.

24. Lutz TA (2010) The role of amylin in the control of energy homeostasis. Am J Physiol Regul Integr Comp Physiol 298 R1475-R1484.

25. Reimer RA \& Russell JC (2008) Glucose tolerance, lipids and GLP-1 secretion in JCR:LA-cp rats fed a high protein fiber diet. Obesity 16, 40-46.

26. Reimer RA \& McBurney MI (1996) Dietary fiber modulates intestinal proglucagon messenger ribonucleic acid and postprandial secretion of glucagon-like peptide- 1 and insulin in rats. Endocrinology 137, 3948-3956.

27. Reimer RA, Thomson ABR, Rajotte R, et al. (1997) A physiological level of rhubarb fiber increases proglucagon gene expression and modulates intestinal glucose uptake in rats. J Nutr 127, 1923-1928.

28. Jacobs LR \& Lupton JR (1984) Effect of dietary fibers on rat large bowel mucosal growth and cell proliferation. $\mathrm{Am} \mathrm{J}$ Physiol 246, G378-G385.

29. Del Prado M, Delgado G \& Villalpando S (1997) Maternal lipid intake during pregnancy and lactation alters milk composition and production and litter growth in rats. J Nutr 127, 458-462.

30. German JB, Freeman SL, Lebrilla CB, et al. (2008) Human milk oligosaccharides: evolution, structures and bioselectivity as substrates for intestinal bacteria. Nestle Nutr Workshop Ser Pediatr Program 62, 205-218.

31. Blass EM \& Teicher MH (1980) Suckling. Nature 210, 15-22.

32. Drozdowski LA \& Thomson AB (2006) Intestinal sugar transport. World J Gastroenterol 12, 1657-1670.

33. Ferraris RP (2001) Dietary and developmental regulation of intestinal sugar transport. Biochem J 360, 265-276.

34. Douard V \& Ferraris RP (2008) Regulation of the fructose transporter GLUT5 in health and disease. Am J Physiol Endocrinol Metab 295, E227-E237.

35. Massimino S, McBurney MI, Field CJ, et al. (1998) Fermentable dietary fiber increases GLP-1 secretion and improves glucose homeostasis despite intestinal glucose transport capacity in healthy dogs. J Nutr $\mathbf{1 2 8}$ $1786-1793$.

36. Parnell JA \& Reimer RA (2009) Effect of prebiotic fiber supplementation on hepatic gene expression and serum lipids: a dose-response study in JCR: LA-cp rats. Br J Nutr 103, 1577-1584.

37. Farmer SR (2008) Molecular determinants of brown adipocyte formation and function. Genes Dev $\mathbf{2 2}$, 1269-1275.

38. Petzke KJ, Friedrich M, Metges CC, et al. (2005) Long-term dietary high protein intake up-regulates tissue specific gene expression of uncoupling proteins 1 and 2 in rats. Eur J Nutr 44, 414-421.

39. Nakazato K \& Song H (2008) Increased oxidative properties of gastrocnemius in rats fed on a high-protein diet. $J$ Nutr Biochem 19, 26-32.

40. Zhao Z-J \& Wang D-H (2007) Effects of diet quality on energy budgets and thermogenesis in Brandt's voles. Comp Biochem Physiol Part A 148, 168-177.

41. Sugatani J, Wada T, Osabe M, et al. (2006) Dietary inulin alleviates hepatic steatosis and xenobiotics-induced liver injury in rats fed a high-fat and high-sucrose diet: association with the suppression of hepatic cytochrome 450 and hepatocyte nuclear factor 4áexpression. Drug Metab Dispos 34, $1677-1687$.

42. Stroubini T, Perelas A, Liapi C, et al. (2009) Serum adiponectin and resistin in rats under three isocaloric diets: The effect of sibutramine. Cytokine 46, 171-175. 
43. Herder C, Peltonen M, Koenig W, et al. (2009) Anti-inflammatory effect of lifestyle changes in the Finnish Diabetes Prevention Study. Diabetologia 52, 433-442.

44. Ma Y, Hebert JR, Li W, et al. (2008) Association between dietary fiber and markers of systemic inflammation in the Women's Health Initiative Observational Study. Nutrition 24, 941-949.

45. Kallio P, Kolehmainen M, Laaksonen DE, et al. (2008) Inflammation markers are modulated by responses to diets differing in postprandial insulin responses in individuals with the metabolic syndrome. Am J Clin Nutr 87, 1497-1503.

46. Neyrinck AM, De Backer F, Cani PD, et al. (2008) Immunomodulatory properties of two wheat bran fractions - aleurone-enriched and crude fractions - in obese mice fed a high fat diet. Int Immunopharmacol 8, 1423-1432.

47. Cani PD, Neyrinck AM, Maton N, et al. (2005) Oligofructose promotes satiety in rats fed a high-fat diet: involvement of glucagon-like peptide-1. Obes Res 13, 1000-1007. 